\title{
Horizontal Ridge Augmentation of a Single Atrophic Site in the Anterior Maxilla Using Hydroxyapatite and rhBMP-2
}

\author{
Augmento Óseo Horizontal de Reborde Alveolar en Sitio Atrófico \\ Único en Maxila Anterior Usando Hidroxiapatita y rhBMP-2
}

Gustavo Maître ${ }^{1}$; Daniel Farias²; Eduardo de Moraes $^{3}$; Roberto Sacco ${ }^{4,5,6}$; Rebecca Ball ${ }^{5}$; Ziyad S. Haidar ${ }^{7,8}$ \& Sergio Olate $^{9}$

MAITRE, G.; FARIAS, D.; DE MORAES, E.; SACCO, R.; BALL, R.; HAIDAR, Z. S. \& OLATE, S. Horizontal Ridge Augmentation of a Single Atrophic Site in the Anterior Maxilla Using Hydroxyapatite and rhBMP-2. Int. J. Morphol., 38(5):1426-1433, 2020.

SUMMARY: Bone morphogenetic protein (rhBMP-2) is a powerful osteo-inductive growth factor widely used in bone reconstruction and both the vehicle used to administer it and the scaffold substrate could determine its success in clinical situations. The aim was to analyse the clinical behaviour of dental implants placed in single alveolar ridges with a horizontal deficiency in the maxillary anterior region that were reconstructed horizontally with rhBMP-2 and porous hydroxyapatite (HA). Inclusion criteria were both males and females, between the ages of 18 and 29 with single tooth loss of one upper incisor. Cone Beam Computed Tomography (CBCT) was used to take measurements prior to bone augmentation and again prior to the implant insertion. Surgery was carried out under local anaesthetic. In the primary procedure, bone substitute was introduced using porous HA and rhBMP-2; after 4 to 5 months, dental implant surgery was carried out and the implant placed; after 3 months of consolidation the provisional prosthesis was placed and then a definitive restoration was placed. Variables were analysed using the t-test with a p-value of $<0.05$ in order to assess statistical significance. Thirteen subjects were included ( 6 females and 7 males). Bone augmentation resulted in a bone gain of $4.15 \mathrm{~mm}(\mathrm{p}=0.023)$, which was shown to be statistically significant. All of the grafts placed were successful and 13 implants were placed, using torques between 30 and $70 \mathrm{~N}$, without complications. For the final prostheses, 11 were screw retained and 2 were cemented in place. The horizontal bone augmentation using HA and rhBMP-2 is an efficient technique for single bone defects in the anterior maxillary area; clinical trials on a larger scale are needed to confirm these results.

KEY WORDS: rhBMP-2; hydroxyapatite; osteoinduction; bone graft.

\section{INTRODUCTION}

Atrophy of the alveolar ridge in the maxilla and mandible is a common occurrence following tooth loss. This condition is particularly complex in the anterior region due to the aesthetic implications. Treatment for alveolar preservation immediately following the loss of a tooth have been proposed, however there are still no clearly defined protocols. Furthermore, differences in biomaterials may show varying results in bone regeneration prior to the placement of implants (Cantin et al., 2015). Chappius et al . (2017) showed that after tooth loss, tissue loss occurs in the anterior zone of the alveolus due to the thin bone biotype (thickness less than $1 \mathrm{~mm}$ of the buccal bone). A volumetric change after tooth loss is therefore to be expected due to this loss of buccal bone.

Horizontal bone loss has been treated with different techniques. Bone augmentation with autogenous bone grafts installed as a block, have a long history of success (Buser et al., 1996; Schwartz-Arad et al., 2005). It is versatile in application, however the morbidity involved in the use of a second surgery site, remains a disadvantage. Researchers are therefore trying to circumvent this with the use of biomaterials.

\footnotetext{
${ }^{1}$ Master of Dental Sciences, Dental School, University of La Frontera, Temuco, Chile.

${ }^{2}$ Programa de Especialización en Implantología Oral, Universidad de los Andes, Santiago, Chile.

${ }^{3}$ Private Practice, Rio de Janeiro, RJ, Brazil.

${ }^{4}$ Oral Surgery Department, Barts and the London School of Medicine and Dentistry, London, UK.

${ }^{5}$ Oral Surgery Department, King's College Hospital, London, UK.

${ }^{6}$ Oral Surgery Department, Division of Dentistry Manchester University, Manchester, UK.

${ }^{7}$ BioMAT'X, Facultad de Odontología, Universidad de los Andes, Santiago 7550000, Chile.

${ }^{8}$ Centro de Investigación e Innovación Biomédica (CIIB), Facultad de Medicina, Universidad de los Andes, Santiago 7550000, Chile

${ }^{9}$ Division of Oral, Facial and Maxillofacial Surgery, Dental School \& Center of Excellence in Morphological and Surgical Studies, University of La Frontera, Temuco, Chile.
} 
Reconstructions based exclusively on the use of xenogenic, homogenic or alloplastic biomaterials have produced variable results. This is probably due to variations in the substitution rates and because a large part of the osseointegration of the implant occurs into the biomaterial zone, which remains in place in the regenerated site. The combined use of PRF and membranes could improve results, however doubts remain about its application in complex bone defects (Kuchler \& von Arx, 2014; Zumarán et al., 2018).

Bone morphogenetic protein is a growth factor which offers the advantage of being a powerful bone inductor7. Its application within the fields of oral surgery, has proved successful in a number of cases, although defined specific techniques for bone augmentation in the alveolar ridge are limited (Uribe et al., 2017).

The vehicle used for the application of rhBMP-2 is an important factor to facilitate bone matrix formation and to obtain clinically satisfactory results (Raina et al., 2018). The osteo-conduction vehicle, which acts as a scaffold for bone regeneration, must be properly applied to provide mechanical stability and allow regeneration at the site. The aim of this research is to analyse the clinical characteristic of horizontal reconstruction with BMP-2 and porous hydroxyapatite of alveolar ridge in the short term.

\section{MATERIAL AND METHOD}

A longitudinal study was designed, respecting the directives of the Helsinki Declaration for clinical research.. Patients in the study groups were aged over 18 years, ASA I or II, and could be of either sex. Each participant signed an informed consent and treatment was carried out in private practice.

Cone beam computed tomography (CBCT) was used for diagnosis and treatment planning. Subjects who needed a single tooth replacement in the anterior maxillary region, where the residual width of the site was equal to or less than $4 \mathrm{~mm}$ and the residual height had a maximum loss of $2 \mathrm{~mm}$ or less, were included in the study.

General exclusion criteria were: acute myocardial infarction within the past 6 months, uncontrolled coagulation disorders, uncontrolled metabolic diseases (diabetes mellitus, bone pathologies), psychological or psychiatric problems, smokers, patients treated with radiotherapy to the head/ neck district and patients treated with bisphosphonates. Local exclusion criteria were oral infections, uncontrolled periodontal disease, subjects who needed treatment in more than one surgical site or had edentulous spaces in the molar regions,
After 4 to 5 months, a secondary surgery was carried out to place the implants; at this stage a second routine CBCT was taken for use in surgical planning. Measurements were taken and compared with the initial CBCT. Measurements to identify bone gain were taken in both the middle and interproximal zones.

Horizontal augmentation surgery with rhBMP-2. The first alveolar bone reconstruction surgery (Figs. 1 and 2) was carried out using conventional parameters, with a fullthickness mucoperiosteal flap in order to ensure primary closure of the wound. The bone recipient site was roughened with a low speed round carbide bur. During this stage, the porous HA particles (osteo-conductor) and the rhBMP2 (osteo-inductor) were applied (Novosis ${ }^{\circledR}-D e n t ; ~ C G B i o$ Co.,Ltd, Gyeonggi-do, Korea); the rhBMP-2 solution (1mg/ $\mathrm{ml})$ was soaked into the HA particles( $80 \%$ porosity and avg.300_m diameter) allowing an activation period of 10minutes to ensure hydration and flow through the pores of the HA particles. The biomaterial was then placed in the surgical site, with the aim of obtaining a minimum augmentation of 4 to $5 \mathrm{~mm}$ in each case. A fast resorbing microporous collagen membrane (Collatape, Zimmer Biomet, USA) was used to stabilise and protect the grafted zone and the wound was sutured with 4-0 Vicryl.

Implant placement surgery. The implant placement surgery followed current conventions and was carried out 4 to 5 months after the initial surgery. The technique used was either direct drilling without a flap, or raising a full-thickness flap with minimal tissue displacement; ie.no lateral incision of the flap was carried out. Some cases were planned with guided surgery, while others used a conventional technique; in both types a conical implant $3.5 \times 11 \mathrm{~mm}$ or $3.5 \times 10 \mathrm{~mm}$ (Flash Model, Conexao Sistema de Protese, Sao Paulo, Brazil) was inserted, obtaining primary stability between $30 \mathrm{~N}$ and $70 \mathrm{~N}$, following a $2.8 \mathrm{~mm}$ diameter final drilling. As a standard protocol, a submerged technique was implemented.

The third intervention was installing a healing cap and this took place 3 months after implant surgery. A repositioned flap technique was used to improve the aesthetic result and the condition of the peri-implant soft tissues. After 2 weeks, the provisional crown was constructed, and subsequently the definitive fixed prosthesis was attached to the implant; in most cases these were screw-type (Fig. 3). No follow up data was included in this research.

\section{Alveolar ridge reconstruction dimensional changes. A} CBCT measurement was performed by a radiologist. The measurements included were obtained in a standardised fashion way. The analysis was carried out by measuring the alveolar ridge dimension in two planes. In the coronal view, 

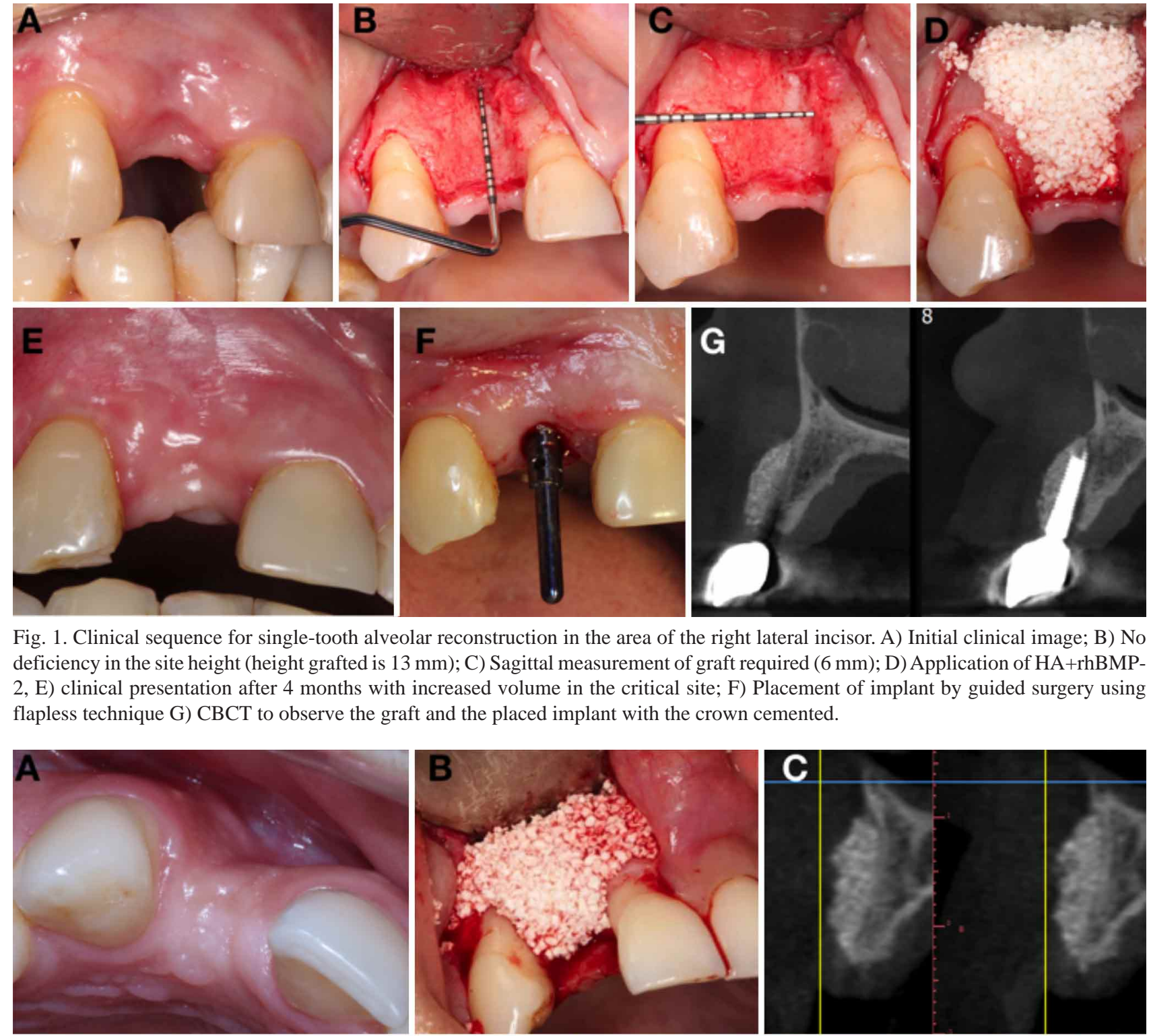

Fig. 1. Clinical sequence for single-tooth alveolar reconstruction in the area of the right lateral incisor. A) Initial clinical image; B) No deficiency in the site height (height grafted is $13 \mathrm{~mm}$ ); C) Sagittal measurement of graft required (6 mm); D) Application of HA+rhBMP2, E) clinical presentation after 4 months with increased volume in the critical site; F) Placement of implant by guided surgery using flapless technique G) CBCT to observe the graft and the placed implant with the crown cemented.

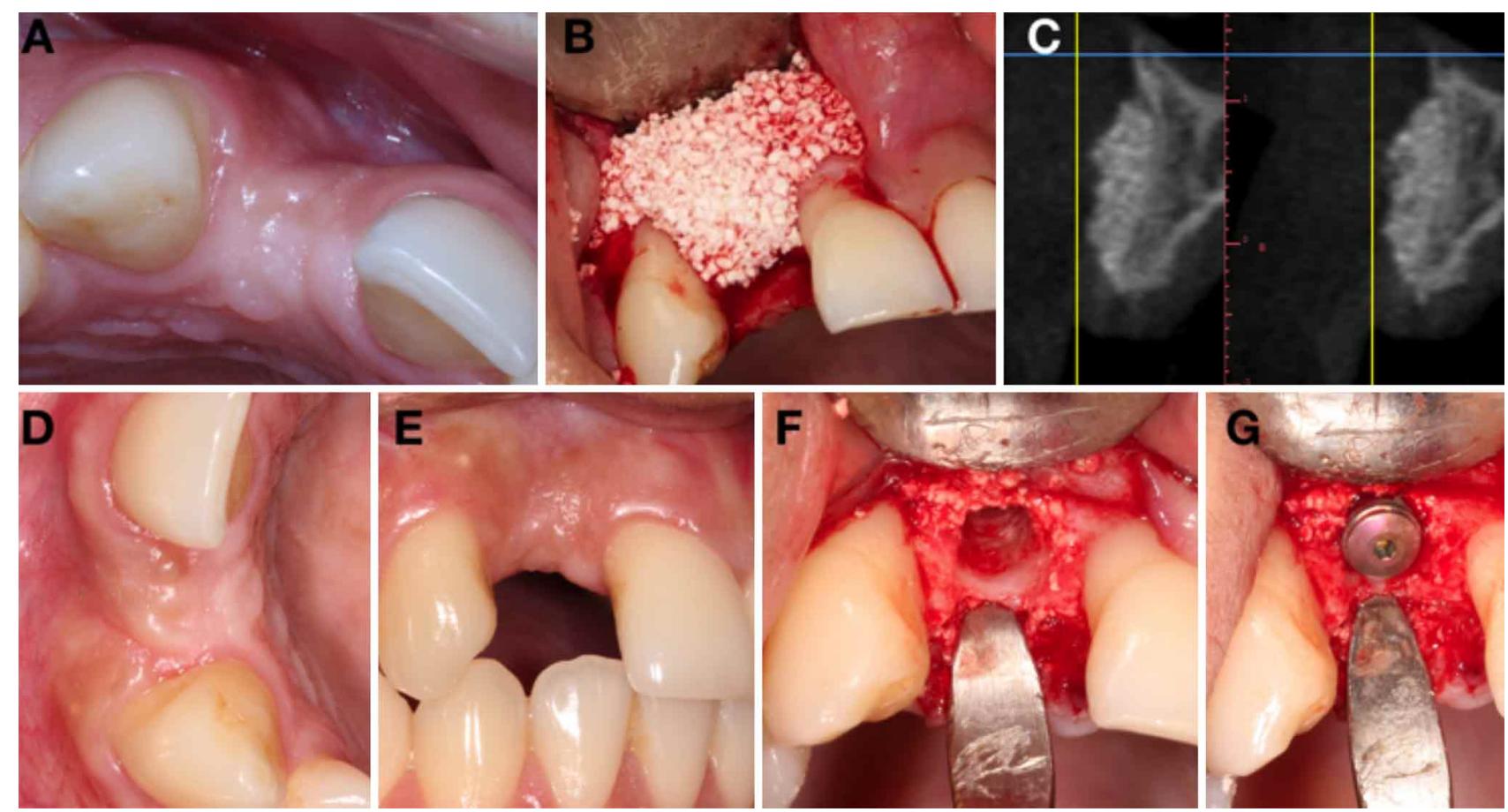

Fig. 2. Clinical sequence for single-tooth alveolar reconstruction in the area of the right lateral incisor. A) Initial clinical image with a large buccal defect; B) Application of HA+rhBMP-2; C) CBCT image showing the materials after grafting with well-defined differences between the graft and native bone; D) and E) Clinical image prior to implant insertion showing improvement compared to the initial stage; F) Clinical image of the surgical site before placement of the implant, with particles of HA still present; G) Implant placed with $40 \mathrm{~N}$ torque. 


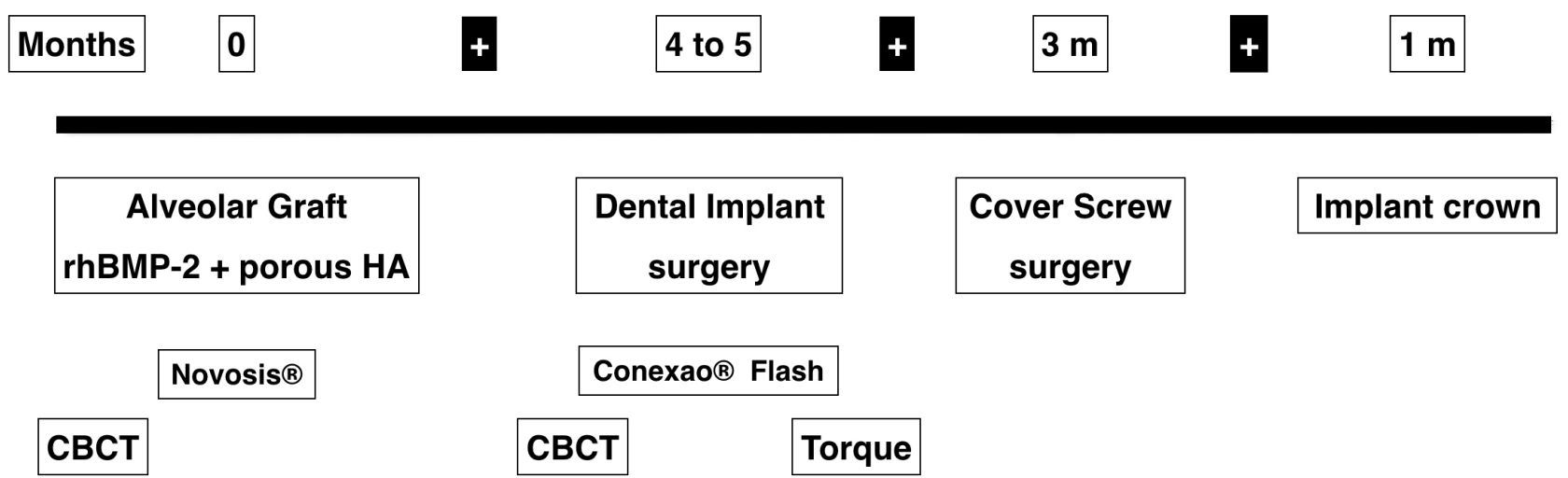

Fig. 3. Sequence of the study for the horizontal augmentation of the alveolar ridge usng BMP an HA.

the midpoint between the anterior and posterior teeth was selected and a vertical line, parallel to the roots, was planned. Then, in the sagittal section $5 \mathrm{~mm}$ below the coronal margin of the ridge were selected the key area; a perpendicular line was made to take the width of the ridge from the anterior to posterior point. The same observer repeated this technique twice obtained a kappa factor of, 0.88 considered good for the protocol (Fig. 4).

Clinical variables included for analysis by CBCT were: the volume of bone obtained in reconstruction, primary stability of the implant and bone regeneration Data was analysed from two bone measurements with the kappa analysis. Statistical analysis was undertaken using ANOVA and the t-test; a $\mathrm{p}$ value of $<0.05$ was considered to be statistically significant.

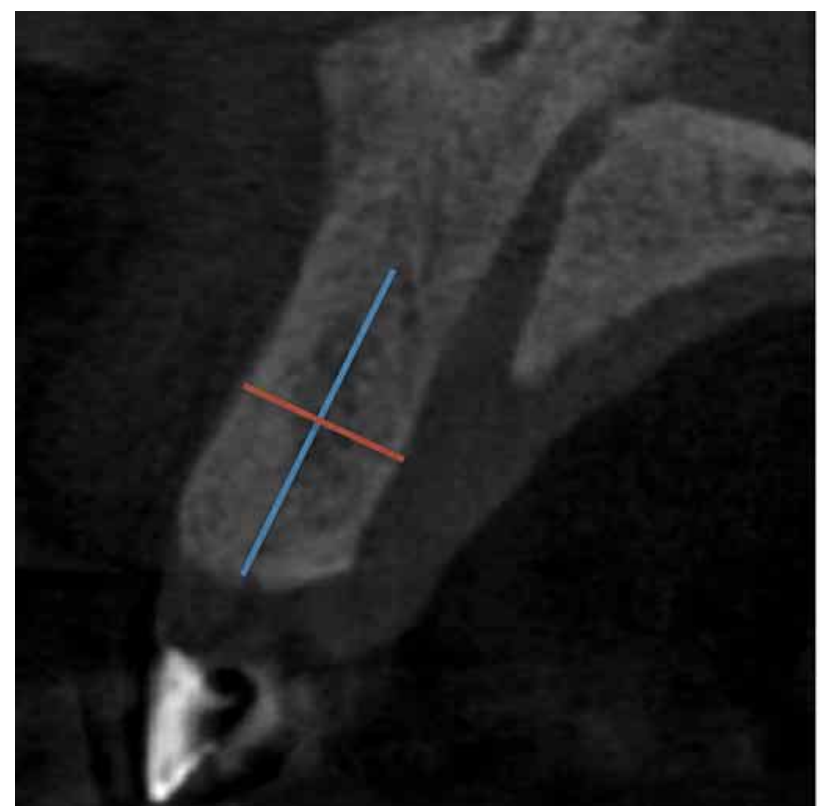

Biopsy was performed in some cases at the same time of implant placement including the grafted bone/recipient site interface A bone sample measuring approximately 2.5 $\mathrm{mm}$ diameter and 5-7 $\mathrm{mm}$ long was removed with a trephine burr of $3 \mathrm{~mm}$ outer diameter, accompanied by a copious irrigation. The specimen was carefully removed from the trephine burr and the part of the biopsy corresponding to the buccal graft's cortical plate was labeled by black Indian ink, for better orientation during histology examination.

The specimens were fixed in $10 \%$ paraformoldehyde, decalcified for four days in a $20 \%$ aqueous solution of sodium citrate and $12.5 \%$ aqueous solution of formic acid before being embedded in paraffin. The samples were staining with hematoxylin/eosin (HE) for routine analysis of the bone repair process using a descriptive analysis.

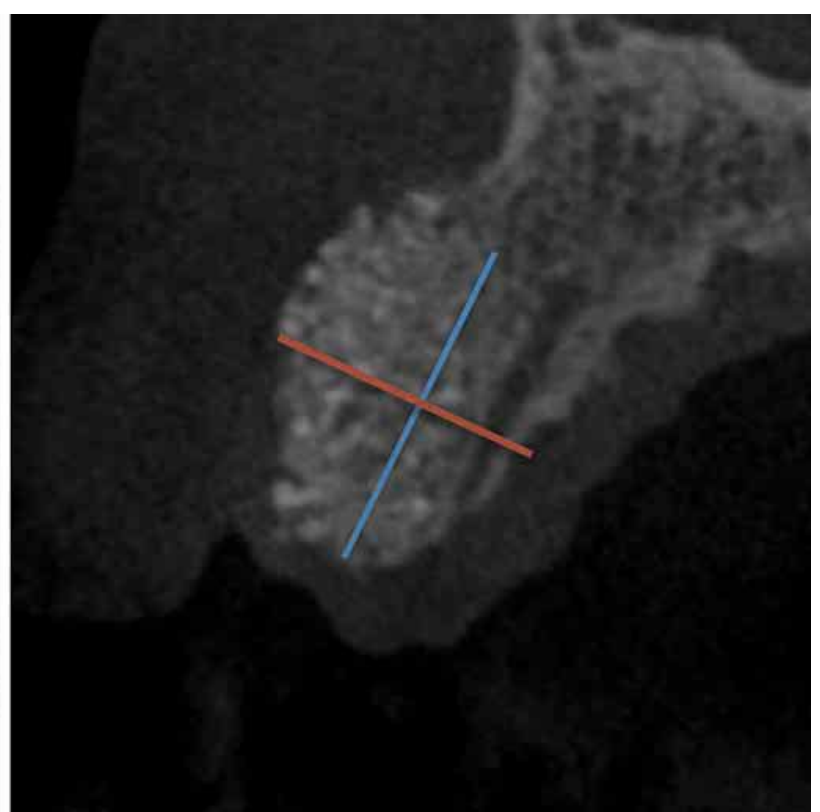

Fig. 4. CBCT used to measurement of the ridge defect before the graft and before of implant insertion. 5mm below marginal crest was selected to make a sagittal measurement. 


\section{RESULTS}

The 13 patients, 7 males and 6 females, were included in the study, with an age range of between 19 and 28 years (mean 23.2 years). Surgery was carried out without complications in all patients.

During the first intervention for bone reconstruction, adequate healing was observed in all cases. Primary closure was seen in all patients and none of the inserted grafts were lost. The reconstruction surgery sites were central incisor ( 8 cases) and lateral incisor (5 cases). Tooth loss had occurred predominantly due to dento-alveolar trauma or failure of endodontic treatments.

Prior to reconstruction, bone thicknesses measured between 2.5 and $4.0 \mathrm{~mm}$ (mean $2.75 \pm 0.9 \mathrm{~mm}$ ). 4 to 5 months after the primary surgery, bone thicknesses measured between 4.5 and $8.2 \mathrm{~mm}$ (mean $6.9 \pm 1.95 \mathrm{~mm}$ ). This gave a statistically significant average increase in bone thickness of $4.15 \mathrm{~mm}$ ( $\mathrm{p}=0.023$ ) (Fig. 4).

In the second surgery, $3.5 \mathrm{~mm}$ Morse taper connection implants were used. The surgical site was prepared with the conventional drill sequencing and the implant was inserted to $1 \mathrm{~mm}$ below the bone margin. A torque of 30 to $70 \mathrm{~N}$ was used for all the 13 implants and in all cases they were inserted using a two-phase protocol. Only 4 cases required an insertion torque of less than $40 \mathrm{~N}$. After 3 months, a healing cap was placed which was then followed by the definitive restoration, with prostheses screwed in place in 11 cases, and cemented in 2 (due to limitations in the angle of implant placement).

In the CBCT image the whole periphery of the implant was covered by the biomaterial (porous HA and rhBMP-2) or by native bone; no significant reduction was observed in the volume of the implanted biomaterial. Histological samples were obtained by using a trephine bur in three cases because the implant diameter was $3.5 \mathrm{~mm}$ and was difficult to obtain an adequate histological sample in all the reconstructed site considering the size of the sample to not modified the primary stability of the implant; however, in these cases was observed bone formation in presence of the HA particles; this was enough to support the implant insertion.

\section{DISCUSSION}

In this research we analysed horizontal augmentation in single-tooth sites in the anterior section of the maxilla. rhBMP-2 is one of the most powerful osteo-inducer molecules identified to date and has been used in varying clinical situations. In its current format, it requires a vehicle and this is significant as the biological half-life is less than 12 hours (Ruhé et al., 2006). The application of high initial doses of BMP has not been fully studied, and the use of controlled release doses may be more efficient for speed, in terms of capacity for new bone formation.

Some research indicated that rhBMP-2 and rhBMP7 may accelerate bone formation, however, they may also accelerate induction of osteoclasts and cause premature bone resorption by RANKL-RANK activation and signalling. This however, has not been fully studied (Kaneko et al., 2000; Seeherman et al., 2010) and the uncertainty may explain some of the published results related to the clinical application of rhBMP-2. For example Raina et al. concluded that rhBMP-2 induced premature bone resorption due to osteoclastic activity. This may have reduced total bone formation in comparison with other rhBMP insertion models. Thus the vehicle plays an important role as it can slow down degradation and generate a longer time period for new bone formation. Some pre-clinical studies have indicated an inverse dose-effect ratio, implying that the application of a dose of rhBMP-2 greater than the optimum (not confirmed value) could have a negative impact on bone formation, delaying bone maturation (Wikesjö et al., 2008a; Wikesjö et al., 2008b).

In these situations, new strategies have evolved for rhBMP-2 application. In one of these, Schorn et al. (2017) used rhBMP-2 in conjunction with vascular endothelial growth factor (VGEF), obtaining a greater augmentation of bone and greater bone-implant contact in experimental models. Shim et al. (2014) created a rhBMP-2 matrix by 3D printing with good initial results in the printing stage but with conflicting experimental results.

In our study, porous hydroxyapatite (HA) was used in conjunction with rhBMP-2; other materials that can be used in bone regeneration are polymers, or polymers with mixtures of inorganic elements, such as calcium sulphate and calcium phosphate. These can be classified as macroporous or microporous depending on their porosity structure and size (Karageorgiou \& Kaplan, 2005). Porosity allows cell migration through the canaliculi; when these are very small, vascular flow is diminished but when their size is greatly increased, the mechanical strength of the material diminishes (Alister et al., 2019). 
Naujokat et al. (2020) studied ectopic bone formation in 3 groups of muscle tissue, using one cube of bovine HA, one biphase cube of HA and tricalcium phosphate, and one cube based on printed titanium. Perforations were created in the cubes in order to install a collagen membrane with cells from the iliac crest and rhBMP-2. Eight weeks later, in re-entry surgery, they installed the implants in the cubes. Bone formation occurred in all the cubes, however, the bovine block showed the smallest amount of bone formation.

de Freitas et al. (2013) carried out a systematic review of the clinical applications of rhBMP-2 in reconstructive dentoalveolar surgery for implant placement. They concluded that it was difficult to compare results with other research due to differences in the doses used $(0.43,0.75$ and $1.5 \mathrm{mg} / \mathrm{mL}$ in different applications) as well as the quantity of rhBMP-2 incorporated and the type of defects treated. de Freitas et al. (2013) highlighted the potential of rhBMP-2 and the positive results obtained in the majority of studies.

Triplett et al. (2009) compared differences in the bone height and width with autogenous bone and rhBMP-2 in maxillary sinus lifts. However, this clinical model had significant features which were not considered (e. g. presence of adjacent teeth, degree of sinus pneumatization and corticalisation of the adjacent bone) and therefore this change may not be associated solely with the type of material used but due to clinical variables (Parra et al., 2017). In the authors' opinion, it is more difficult to study the real impact of biomaterials in horizontal or vertical defects of the alveolar ridge than in other situations requiring bone augmentation, such as maxillary sinus lifts.

Using an autogenous block graft for augmenting the width, Buser et al. observed an increase in bone of $3.5 \mathrm{~mm}$ (ranges of 1 to $7.5 \mathrm{~mm}$ ) whilst Schwartz-Arad et al. reported a mean bone augmentation of $3.8 \mathrm{~mm}$ with a success rate close to $88 \%$, using the same reconstruction technique. With autogenous bone, the width of graft is around $3.5 \mathrm{~mm}$ because the intraoral donor site cannot provide a thickness greater than $4 \mathrm{~mm}$ (to avoid neurological or morphological alterations) (Velásquez et al., 2017; Parra et al., 2018). Taking this into consideration, obtaining a $4 \mathrm{~mm}$ bone increase with the technique described in this investigation, would appear appropriate and efficient for the insertion and retention of implants.

Another study model carried out by Misch et al. (2017), used allogenous blocks soaked with collagen sponge and rhBMP-2 in 21 patients. They identified bone augmentation in all cases, with no loss ofany blocks. After 6 months they placed implants and observed a reduction of the bone volume in all cases. With this technique they achieved a bone gain of 2.8 to $7.7 \mathrm{~mm}$ (mean $4.61 \pm 0.82$ $\mathrm{mm})$.

de Freitas et al. (2105) carried out a study using collagen sponge with rhBMP-2 in the maxillary zone, placed with titanium mesh. They concluded that the sites which received rhBMP-2 presented less horizontal bone loss than the autogenous grafts; even so, none of the implants were lost and all required a placement torque greater than $30 \mathrm{~N} /$ $\mathrm{cm} 2$. Finally, no significant differences were observed in terms of bone gain and implant stability in comparisons between gain with BMP-2 and the autogenous graft.

Geurs et al. (2008) treated a sequence of patients for horizontal bone augmentation with slow resorption membranes, allograft and a thermoplastic vehicle. They reported bone gains of 2.4 to $5.2 \mathrm{~mm}$, similar in value to our study results. Another similar study was carried out by Toscano et al. (2010), who used an allograft and a degradable thermoplastic vehicle covered by a resorbable membrane, in the horizontal augmentation of 73 patients, obtaining a mean bone gain of $3.5 \mathrm{~mm}$ (range 3 to $6 \mathrm{~mm}$ ). Our results showed a mean bone gain of $4.15 \mathrm{~mm}$ after 4 to 5 months, which was a significant difference $(p=0.023)$. In all cases, the implants were installed with appropriate torque and rehabilitation occurred without complications. Clinically however, a few remaining particles of HA were observed.

Other authors have shown variables results in terms of bone formation using mixtures of rhBMP-2 with particulate bone material of bovine origin (Jung et al., 2003; Kao et al., 2012), which may be associated with the rhBMP vehicle. de Freitas et al. (2015) used rhBMP-2 and collagen sponge with bone gains of 1.5 to $3 \mathrm{~mm}$. They considered that the titanium mesh may have been an important factor. In our study we only used a collagen membrane but did not use any kind of mechanical support. It is possible that the structural stability offered by porous HA was a positive factor for the stability of the bone volume, and the slow degradation rate allowed maintenance of this volume. As in our study, Kim et al. (2017) obtained horizontal augmentations using rhBMP-2 and porous HA as the vehicle and concluded that the bone augmentation was useful for implant placement, with no reported complications for the patients.

It may be concluded that the use of porous HA and rhBMP-2 gives predictable outcomes in clinical application for horizontal augmentation of the anterior maxillary region. More extensive investigations with larger sample sizes, as well as clinical trials, are required to corroborate these results. 
MAITRE, G.; FARIAS, D.; DE MORAES, E.; SACCO, R.; BALL, R.; HAIDAR, Z. S.; OLATE, S. Augmento Óseo Horizontal de Reborde Alveolar en Sitio Atrófico Unico en Maxila Anterior Usando Hidroxiapatita y rhBMP-2. Int. J. Morphol. , $38(5): 1426-1433,2020$.

RESUMEN: La proteína ósea morfogenética (BMP-2) es un potente osteoinductor utilizado ampliamente en técnicas reconstructivas; el vehículo de instalación es determinante en su evolución. El objetivo fue analizar el comportamiento clínico de implantes dentales instalados en rebordes alveolares únicos con deficiencia horizontal del sector anterior reconstruida horizontalmente con BMP-2 e hidroxiapatita (HA) porosa. Fueron incluidos sujetos de ambos sexos de entre 18 y 29 años, con pérdida dentaria unitaria a nivel de incisivos superiores. Se utilizó tomografía computadorizada para realizar mediciones en las etapas previa a la instalación del injerto y previo a la instalación del implante. Las cirugías fueron realizadas bajo anestesia local. En la primera intervención se realizó la instalación del injerto óseo utilizando HA porosa y BMP-2; después de 4 a 5 meses se realizó la instalación del implante dental; 3 meses después se realizó la conexión protésica y rehabilitación final. Las variables fueron estudiadas con la prueba t test considerando el valor de $p<0,05$ para considerar significancia estadística.Trece sujetos fueron incluidos (6 mujeres y 7 hombres); con la reconstrucción ósea se obtuvo una ganancia ósea de $4,15 \mathrm{~mm}(\mathrm{p}=0.023)$ que fue estadísticamente significativo. No existió pérdida en ningún injerto realizado; se instalaron 13 implantes con torques entre $30 \mathrm{y}$ $70 \mathrm{~N}$ sin complicaciones; se realizaron prótesis fijas atornilladas en 11 casos y cementadas en 2 casos. La técnica con HA y BMP2 es eficiente para reconstruir defectos horizontales en perdidas unitarias del sector anterior maxilar; ensayos clínicos de mayor escala son necesarios para confirmar estos resultados.

PALABRAS CLAVE: BMP-2; Hidroxiapatita; Osteoinduccción; Injerto óseo.

\section{REFERENCES}

Alister, J. P.; Uribe, F.; Vásquez, B.; Fariña, R. \& Olate, S. Characterization of bone substitute b-TCP block for maxillofacial reconstruction. Int. J. Morphol., 37(1):82-6, 2019.

Buser, D; Dula, A.; Hirt, H. P. \& Schenk, R. K. Lateral ridge augmentation using autografts and barrier membranes: a clinical study with 40 partially edentulous patients. J. Oral Maxillofac. Surg., 54(4):420-32, 1996.

Cantin, M.; Olate, S.; Fuentes, R. \& Vásquez, B. Alveolar ridge conservation by early bone formation after tooth extraction in rabbits: a histomorphological study. Int. J. Morphol., 33(1):36974, 2015 .

Chappius, V.; Araújo, M. G. \& Buser, D. Clinical relevance of dimensional bone and soft tissue alterations post-extraction in esthetic sites. Periodontol. 2000, 73(1):73-83, 2017.

de Freitas, R. M.; Spin-Neto, R.; Marcantonio Junior, E.; Pereira, L. A. V. D.; Wikesjö, U. M. E. \& Susin, C. Alveolar ridge and maxillary sinus augmentation using rhBMP-2: a systematic review. Clin. Implant Dent. Relat. Res., 17 Suppl. 1:e192-201, 2015.

de Freitas, R. M.; Susin, C.; Spin-Neto, R.; Marcantonio, C.; Wikesjö, U. M. E.; Pereira, L. A. V. D. \& Marcantonio Jr., E. Horizontal ridge augmentation of the atrophic anterior maxilla using rhBMP2/ACS or autogenous bone grafts: a proof-of-concept randomized clinical trial. J. Clin. Periodontol., 40(10):968-75, 2013.

Geurs, N. C.; Korostoff, J. M.; Vassilopoulos, P. J.; Kang, T. H.; Jeffcoat, M.; Kellar, R. \& Reddy, M. S. Clinical and histologic assessment of lateral alveolar ridge augmentation using a synthetic long-term bioabsorbable membrane and an allograft. J. Periodontol., 79(7):1133-40, 2008.

Jung, R. E.; Glauser, R.; Schärer, P.; Hämmerle, C. H. F.; Sailer, H. F. \& Weber, F. E. Effect of rhBMP-2 on guided bone regeneration in humans. Clin. Oral Implants Res., 14(5):556-68, 2003.

Kaneko, H.; Arakawa, T.; Mano, H.; Kaneda, T.; Ogasawara, A.; Nakagawa, M.; Toyama, Y.; Yabe, Y.; Kumegawa, M. \& Hakeda, Y. Direct stimulation of osteoclastic bone resorption by bone morphogenetic protein (BMP)-2 and expression of BMP receptors in mature osteoclasts. Bone, 27(4):479-86, 2000.

Kao, D. W. K.; Kubota, A.; Nevins, M. \& Fiorellini, J. P. The negative effect of combining rhBMP-2 and Bio-Oss on bone formation for maxillary sinus augmentation. Int. J. Periodontics Restorative Dent., 32(1):61-7, 2012.

Karageorgiou, V. \& Kaplan, D. Porosity of 3D biomaterial scaffolds and osteogenesis. Biomaterials, 26(27):5474-91, 2005.

Kim, H. S.; Park, J. C.; Yun, P. Y. \& Kim, Y. K. Evaluation of bone healing using rhBMP-2 soaked hydroxyapatite in ridge augmentation: a prospective observational study. Maxillofac. Plast. Reconstr. Surg., 39(1):40, 2017.

Kuchler, U. \& von Arx, T. Horizontal ridge augmentation in conjunction with or prior to implant placement in the anterior maxilla: a systematic review. Int. J. Oral Maxillofac. Implants, 29 Suppl.:1424, 2014.

Misch, C. M. Bone augmentation using allogeneic bone blocks with recombinant bone morphogenetic protein-2. Implant Dent., 26(6):826-31, 2017.

Naujokat, H.; Açil, Y.; Harder, S.; Lipp, M.; Böhrnsen, F. \& Wilfang, J. Osseointegration of dental implants in ectopic engineered bone in three different scaffold materials. Int. J. Oral Maxillofac. Surg., 49(1):135-42, 2020.

Parra, M.; Jara, J.; Navarro, P.; Vásquez, B. \& Olate, S. Computed tomography-guided bone block harvesting from the mandibular ramus. Int. J. Morphol, 36(1):362-6, 2018.

Parra, M.; Olate, S. \& Cantín, M. Clinical and biological analysis in graftless maxillary sinus lift. J. Korean Assoc. Oral Maxillofac. Surg., 43(4):214-20, 2017

Raina, D. B.; Larsson, D.; Mrkonjic, F.; Isaksson, H.; Kumar, A.; Lidgren, L. \& Tägil, M. Gelatin- hydroxyapatite- calcium sulphate based biomaterial for long term sustained delivery of bone morphogenic protein- 2 and zoledronic acid for increased bone formation: in-vitro and in-vivo carrier properties. J. Control Release, 272:83-96, 2018

Ruhé, P. Q.; Boerman, O. C.; Russel, F. G. M.; Mikos, A. G.; Spauwen, P. H. \& Jansen, J. A. In vivo release of rhBMP-2 loaded porous calcium phosphate cement pretreated with albumin. J. Mater. Sci. Mater. Med., 17(10):919-27, 2006.

Schorn, L.; Sproll, C.; Ommerborn, M.; Naujoks, C.; Kübler, N. R. \& Depprich, R. Vertical bone regeneration using rhBMP-2 and VEGF. Head Face Med., 13:11, 2017.

Schwartz-Arad, D.; Levin, L. \& Sigal, L. Surgical success of intraoral autogenous block onlay bone grafting for alveolar ridge augmentation. Implant Dent., 14(2):131-8, 2005. 
Seeherman, H. J.; Li, X. J.; Bouxsein, M. L. \& Wozney, J. M. rhBMP2 induces transient bone resorption followed by bone formation in a nonhuman primate core-defect model. J. Bone Joint Surg. Am., 92(2):411-26, 2010.

Shim, J. H.; Kim, S. E.; Park, J. Y.; Kundu, J.; Kim, S. W.; Kang, S. S. \& Cho, D. W. Three-dimensional printing of rhBMP-2-loaded scaffolds with long-term delivery for enhanced bone regeneration in a rabbit diaphyseal defect. Tissue Eng. Part A, 20(13-14):198092, 2014.

Toscano, N.; Holtzclaw, D.; Mazor, Z.; Rosen, P.; Horowitz, R. \& Toffler, M. Horizontal ridge augmentation utilizing a composite graft of demineralized freeze-dried allograft, mineralized cortical cancellous chips, and a biologically degradable thermoplastic carrier combined with a resorbable membrane: a retrospective evaluation of 73 consecutively treated cases from private practices. J. Oral Implantol., 36(6):467-74, 2010.

Triplett, R. G.; Nevins, M.; Marx, R. E.; Spagnoli, D. B.; Oates, T. W.; Moy, P. K. \& Boyne, P. J. Pivotal, randomized, parallel evaluation of recombinant human bone morphogenetic protein-2/absorbable collagen sponge and autogenous bone graft for maxillary sinus floor augmentation. J. Oral Maxillofac. Surg., 67(9):1947-60, 2009.

Uribe, F.; Cantín, M.; Alister, J. P.; Vilos, C.; Fariña, R. \& Olate, S. Bone morphogenetic protein and its option as an alveolar cleft treatment. Int. J. Morphol., 35(1):310-8, 2017.

Velásquez, H.; Olate, S.; Días, C.; Navarro, P.; Borie, E. \& de Moraes, M. Quantitation of mandibular symphysis bone as source of bone grafting: description in class I and class III skeletal conditions. $J$. Oral Implantol., 43(3):211-7, 2017.

Wikesjö, U. M. E.; Qahash, M.; Polimeni, G.; Susin, C.; Shanaman, R. H.; Rohrer, M. D.; Wozney, J. M. \& Hall, J. Alveolar ridge augmentation using implants coated with recombinant human bone morphogenetic protein-2: histologic observations. J. Clin. Periodontol., 35(11):1001-10, 2008b.

Wikesjö, U. M. E.; Xiropaidis, A. V.; Qahash, M.; Lim, W. H.; Sorensen, R. G.; Rohrer, M. D.; Wozney, J. M. \& Hall, J. Bone formation at recombinant human bone morphogenetic protein-2-coated titanium implants in the posterior mandible (Type II bone) in dogs. J. Clin. Periodontol., 35(11):985-91, 2008a.

Zumarán, C. C.; Parra, M. V.; Olate, S. A.; Fernández, E. G.; Muñoz, F. T. \& Haidar, Z. S. The 3 R's for platelet-rich fibrin: a "super" tridimensional biomaterial for contemporary naturally-guided oromaxillo-facial soft and hard tissue repair, reconstruction and regeneration. Materials (Basel), 11(8):1293, 2018.

\author{
Corresponding author: \\ Prof. Sergio Olate \\ Universidad de La Frontera \\ Claro Solar 115 \\ Temuco \\ CHILE
}

Email: sergio.olate@ufrontera.cl

Received: 16-05-2020

Accepted: 18-06-2020 